\title{
Continence Training Needs Assessment of Residential Long-Term Care Personal Support Workers
}

\author{
D. Wayne Taylor \\ The Cameron Institute, 1539 King St. E., Preston \\ Cambridge, ON N3H 5N4, Canada \\ Jacqueline J. Cahill \\ The Canadian Continence Foundation \\ Peterborough ON K9J 6Z3, Canada
}

\begin{abstract}
Urinary incontinence (UI) and fecal incontinence (FI) are embarrassing and debilitating conditions that are becoming collectively a major, growing health concern for men and women of all ages worldwide. Recent research showed that professional care-givers in long-term facilities (nursing homes) were not confident in their skills to care for FI residents. This long-term care residential-based study conducted in Ontario Canada was purposed to identify gaps in the knowledge of professional care-givers. Based upon the results of this study there appeared to be room for improvement in the management of both UI and FI in long-term care residences in Ontario. It is recommended that a first tranche of participatory education include topics such as: the causes of FI; the value of using assessments, histories and diaries in moving from treatment to management; dealing with residents that are incontinent as well as depressed.
\end{abstract}

Keywords: Continence, Fecal incontinence, Long-term care, Needs assessment, Nursing homes, Personal support workers, Training Urinary incontinence

\section{INTRODUCTION}

Urinary incontinence (UI) and fecal incontinence (FI) are embarrassing and debilitating conditions that are becoming collectively a major, growing health concern for men and women of all ages worldwide. Many urinary and fecal incontinent consumers do not have access to evidence-based medical therapy and their quality of life suffers because of the stigma inherent. In terms of academic study, interest and understanding, fecal incontinence (FI) is the poor cousin of the incontinence twins.

A search of the electronic academic search engine, Google Scholar, identified over 461,000 articles written about urinary incontinence (UI) compared to only 105,000 that studied FI [1]. Prima facie this is a gross understudy of FI given that the prevalence rate for FI in the non-institutionalized population overall is $18 \%$ [2]; UI has been estimated at $28 \%$ [3]; and the prevalence of FI presenting concurrent with UI (double incontinence) at 55\% [4].

Although the epidemiology, and the socio-economic consequences, of UI have been well-defined in the incontinence literature, the community prevalence and adverse impact of FI remain incompletely understood. The main reason is the use of different interview questions in highly selected and hospital-based populations that has resulted in widely varying reported prevalence rates and impacts [5].

In Canada, the prevalence rate of FI ranged from $2 \%$ in a community-based sample of middle-age subjects and $3 \%$ in the nulligravid secondary school female teenage population, to $8 \%$ in post-partum women following obstetrical anal sphincter injury, and $46 \%$ amongst the elderly in long-term hospitals [5-8].

Qualitative studies and epidemiological data have repeatedly shown that patients do not understand the actual meaning of the word "incontinence", whether this is urinary or fecal, thus both conditions have been often under-reported [9-13]. According to other patient surveys several years will pass beyond onset before incontinent women will present their symptoms to a physician or other health care provider and/or be referred to a specialist $[9,14-16]$ because they: 
- think that the condition is not treatable;

- feel embarrassed; and/or

- think that incontinence is a "normal" part of ageing.

There is a dearth of reliable data about FI as well as studies covering the perception, knowledge and health-care seeking behavior of Canadians with FI. FI is often suffered in silence without seeking health care. Many incontinent patients in Canada are treated by their family physician. These general practitioners have reported that they are not adequately trained to provide proper care for their urinary incontinent patients; they are hesitant to discuss or manage the condition during consultation, and; they often do not arrange follow-up care including timely specialist referral [17].

This study assumed that continence care for residents of long-term care facilities (nursing homes) would be better than that in the community. The average age of a long-term care resident in Ontario is 86 years. Below is a snapshot of long-term care residences in Ontario in 2015 [18]:

- 626 residences licensed and approved to operate in Ontario;

- $57 \%$ of residences are privately owned, $24 \%$ are non-profit/charitable, $17 \%$ are municipal;

- $40 \%$ of long-term care residences are small, with 96 or fewer beds; of these, $41 \%$ are located in rural communities;

- $62 \%$ of residents live with Alzheimer's disease or other dementias;

- $46 \%$ of residents exhibit some level of aggressive behavior;

- $40 \%$ of residents have a psychiatric diagnosis such as anxiety, depression, bipolar disorder or schizophrenia;

- $97 \%$ of residents have two or more chronic diseases;

- $22 \%$ increase in the number of residents who need help with toileting;

- $73 \%$ of staffing is by personal support workers (PSWs - 1 year community college; nonclinical supportive care only), $18 \%$ by registered practical nurses (RPNs - 2.5 year community college; limited scope of nursing practice), and $9 \%$ by registered nurses (RNs -4 year university baccalaureate degree; full nursing scope of practice).

Like many post-industrial jurisdictions, Ontario (and Canada as a whole) has an aging population with an ever-increasing demand for long-term care both residential and in the community. Against this growth in demand is juxtaposed a static supply of long-term care residential beds, a growing acuity, complexity and morbidity of residents, and severe budgetary restraints with little money available for staff development. A long-term care bed is only $1 / 7^{\text {th }}$ of the cost of an acute care bed in a hospital but $3 x$ the cost of delivering care in the community.[19] As business economists would say, long-term care homes are "stuck in the middle" - starved for resources needed to be effective with no real economies of scale for efficiencies.[20]

\section{MAterials AND Methods}

The prevalence of FI in the long-term care residential community is not accurately known but the data above showed that it is increasing. Recent research showed that professional care-givers in long-term facilities (nursing homes) were not confident in their skills to care for FI residents.[21] This longterm care residential-based study conducted in Ontario Canada was purposed to identify gaps in the knowledge of professional care-givers in long-term care facilities to inform educators and administrators the need for in-service training curricula so that those with FI can live a better quality of life and their caregivers can feel more confident in their provision of care.

The objectives of the study were to:

1. Identify the needs of professional care-givers in residential facilities with patients with FI;

2. Identify topics for in-service training.

No previous research of this kind was found. For that reason, the study was an exploratory study using a structured interview protocol of 99 close-ended questions: 36 on a 10-point Likert-type scale; 63 on a binary, 1-0, yes-no scale. Questions were derived from the Self-Learning Package Continence Care Education by the Registered Nurses' Association of Ontario (2006). Professional care-givers - personal support workers (PSWs) as they are called in Ontario - were interviewed in 
person in 3 residential long-term care facilities - one each in an urban, suburban and rural setting that had a high portion of FI residents; 44 interviews were completed. Interview responses were recorded on the questionnaire shared with respondents as well as audio-taped verbatim.

Data were entered into an Excel spreadsheet; frequencies and means calculated for each setting and the sample as a whole; there was no significant difference amongst responses based upon location. Data were analyzed to identify care-giver gaps in knowledge, confidence, education, training and skills in caring for incontinent patients generally and FI patients specifically. [22] No statistical analysis involving significance values was conducted as the sample size was not deemed adequate.

Participants in the study were presented with informed consent documents which identified the title of the project, the names of the researchers and their affiliations, the project's objectives, and assured them that their data would be kept anonymous, confidential and in a safe place. Ethics approval was obtained from a registered medical ethicist.

\section{RESUlTS AND DISCUSSION}

All but one of the staff interviewed were female with an average age of 44 years, ranging from 22 to 69. The majorly had a community college (post-secondary, non-degree) education or equivalent. There were 35 PSWs, 6 health care assistants (PSW equivalents), 1 nursing assistant, 1 RPN and 1RN in the sample interviewed. The average length of practice was 16 years with a range of 1-50 years. The average length of employment with the current employer was 15 years with a range of 1-37 years. Generally, these were long-serving, middle-aged permanent employees well-qualified for their positions.

\section{General Continence Knowledge}

When it came to general continence knowledge respondents fared well. Of the 24 binary questions in this section only $1 / 3^{\text {rd }}$ of the questions had more than $25 \%$ of the respondents not knowing the answer. A number of the PSWs did not have knowledge of the neurological control of the urinary tract, the effect that medications had on continence, or how to identify vaginal prolapse. These were clinical questions which were beyond the scope of practice of a PSW but many did acquire this knowledge "on the job". About 1/3 also did not know how to teach family members about continence or scheduled voiding. Given that this was residential long-term care this response was to be expected.

However between a $1 / 3$ and $1 / 2$ of respondents did not understand the components of either a comprehensive or functional assessment in the management of incontinence, and did not know the questions to ask in taking a resident's continence history. These results were more concerning given that the hope for families and their loved ones is that the latter, if incontinent, are having their incontinence better managed in long-term care, than if on their own, as opposed to just being treated and/or toileted. These responses suggest that the approach taken to incontinence in these facilities was reactive rather proactive, leaving much room for education and improvement for the residents' sakes.

\section{Knowledge about Urinary Incontinence}

Respondent knowledge about urinary incontinence, in particular, was generally poor. This was disconcerting given the rising incidence of UI in long-term care facilities, the rising incidence of dementia amongst long-term care residents and the correlation between dementia and incontinence, and the fact that PSWs are by far the overwhelming number of front-line workers in so-called nursing homes. Most respondents did not know the various types of UI or the differential treatment/ management techniques for each type. These findings were disappointing and contradictory of other studies' findings when UI was better understood than FI; this suggests it could be a sampling anomaly and/or a function of the way the questions were asked.

When it came to being comfortable in dealing with incontinence and the basics of choosing appropriate incontinence products for residents, sizing and fitting, day and night choices, almost all PSWs were quite comfortable and knowledgeable. Regrettably this could also be interpreted (when combined with the finding that incontinence seems to be "treated" more than "managed") as an over reliance upon incontinence products and not helping/being able to help residents actually try to manage their condition.

Sometimes in defense of not knowing something it was often stated that it "was not my job". This sort of attitude was disquieting when dealing with such vulnerable populations as PSWs do. 


\section{Knowledge of Fecal Incontinence}

Ironically, the driving motive behind this research, to investigate health professionals' knowledge of fecal incontinence, was rewarded with respondents generally having a better understanding of FI than UI; the difference between diarrhea and FI; resident cleaning and care of skin irritations; risk factors for FI and so on. There was a lack of knowledge among 1/4-1/3 of PSWs interviewed when it came to knowing the causes of FI. Also, knowledge of managing FI, as opposed to treating it, and the use of a voiding record or diary in doing that was absent amongst some.

\section{Confidence Level}

The overall level of confidence that respondents had when dealing with residents with fecal incontinence was very high with an average score of 8.9/10 across all questions in this category, with 10 being extremely confident. The only exception was in the case of history-taking which was not the responsibility of most, except the nursing staff.

\section{Skill Level}

Respondents also believed that their skill level was high with respect to situations in which residents had fecal incontinence, scoring an average of 9.1/10, with 10 being extremely skillful. Again the only exception was in history-taking where the average was lowered by most not being responsible for this step in care.

\section{In-class Education}

However, the residential care workers interviewed did not feel that their in-class education had been adequate in conveying to them the knowledge and skills to deal with FI. On a10-point scale where 1 equaled no in-class FI education and 10 equaled lots of in-class FI education the average response was 5.6 with the lowest scores (below 5) being in taking histories, dealing with odour, and dealing with residents who were depressed along with being incontinent, in other words, the co-morbid, increasingly complex level of care amongst residents of nursing homes.

\section{Educational Placements}

Similar responses were given when asked about the FI training provided during their educational placements; overall average score was 5.9/10. It was generally felt that a one-month placement amongst residents with low levels of care was not adequate and that longer placements amongst residents with complex levels of care would be more instructive and beneficial for all involved.

\section{"On-the-job" Training}

Interviewees believed they received the most and best of their education and training in resident FI care "on-the-job" training, as differentiated from educational placements, once they had been hired by their employer. Respondents rated their on-the-job training quite highly with an average answer to questions being 7.5/10. The only items that scored below average were, once again, in history-taking, dealing with odour, and dealing with resident depression.

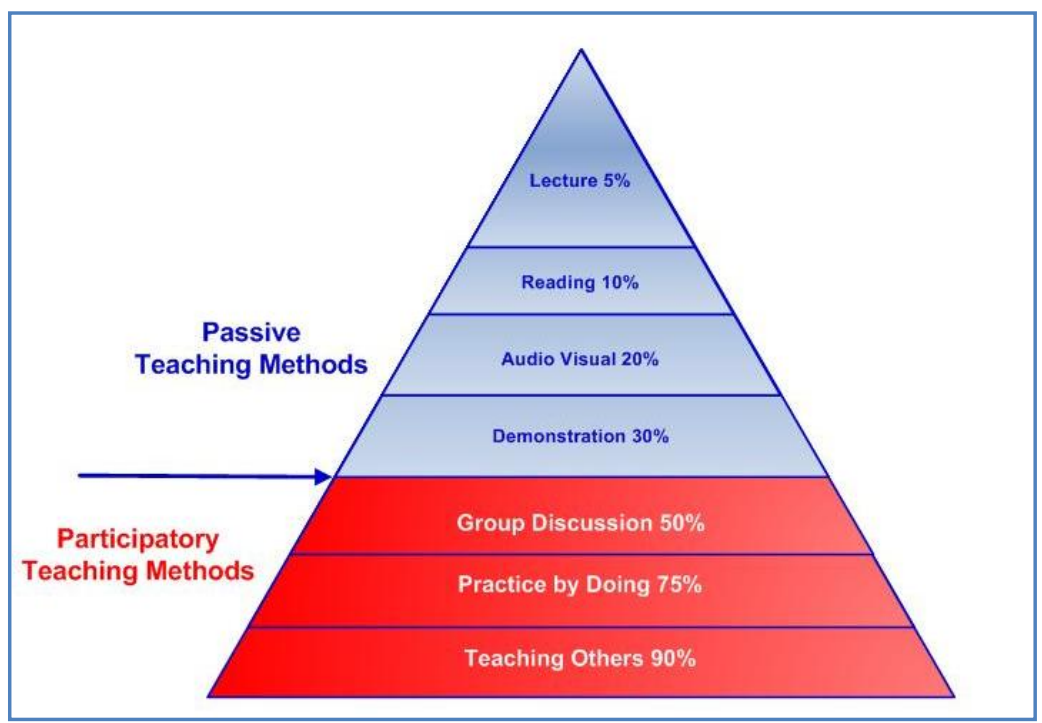

Figure 1. The Adult Learning Pyramid and Percentage of Knowldedge Retention 


\section{Conclusion}

With the growing acuity and complexity of care being required in long-term residences, and the severe restraint of budgets, staffing, time and resources, non-clinical staff - such as personal support workers or health care aides - are being asked to provide extended levels of care. Based upon the results of this study there appears to be room for improvement in the management of both UI and FI in long-term care residences in Ontario and probably elsewhere where the diametrically opposed pressures of demand and supply are similar for long-term care.

Given the demographics of the sample interviewed, and the discrepancies in the relevance of existing in-class education and on-the-job training with respect to FI, it is recommended that any attempt at inservice education follow the principle of "participatory training". The basic tenet of adult education, which is the framework one should adopt for any in-service training of healthcare workers regarding continence, especially for a mature workforce such as studied here, is how much of the knowledge being imparted to learners is retained and subsequently used. From the pyramid in Figure 1 it is clear that participatory teaching methods such as group discussions, practice-by-doing, and the medical model of learn one - do one - teach one will help in retention and use. [23]

This is timely and relevant for Ontario, as long-term care facilities in that province of Canada have been mandated to offer PSWs with in-service training - a reactive response to a growing challenge. Although the first study of its kind, the results could be used proactively by residential long-term care employers and professional groups in any publicly funded health system in a post-industrial country where resources are scarce in meeting the growing complex care needs of elders.

Based upon the results of this study it is recommended that a first tranche of participatory education include topics such as: the causes of FI; the value of using assessments, histories and diaries in moving from treatment to management; dealing with residents that are incontinent as well as depressed. Since the formal education curricula for PSWs seem to fail to address these topics adequately, at least in a way that knowledge is retained, it is also recommended that administrators seek to partner with expert sources external to their organizations, such as patient advocacy groups and vendors of continence supplies and technologies, who will have a specialized understanding, body of knowledge and skills to impart to PSWs and others in the front lines of UI and FI care.

Empowering front line supportive healthcare workers with appropriate knowledge and skills in this area of care will improve the quality of care given to residents and hopefully add to job satisfaction for staff in an otherwise stressful work environment where coping rather than health management is becoming the norm.

\section{Acknowledgements}

The authors wish to express their appreciation for an unrestricted research grant provided by SCA Personal Care.

\section{REFERENCES}

[1] http://scholar.google.ca/scholar?hl=en\&q=urinary+incontinence \&btnG=\&assdt=1\%2C5\&assdtp $=($ Accessed 12/02/2016).

[2] Johanson JF, Lafferty J (1996) Epidemiology of fecal incontinence: the silent affliction. Am J Gastroenterol 91(1):33-36.

[3] Diokno AC, Brock BM, Brown MB, Herzog AR (1986) Prevalence of urinary incontinence and other urological symptoms in the noninstitutionalized elderly. J Urol 136(5):1022-1025.

[4] Roberts RO, Jacobsen SJ, Reilly WT, Pemberton JH, Lieber MM, Talley NJ (1999) Prevalence of combined fecal and urinary incontinence: a community-based study. J Am Geriatr Soc 47(7):837-841.

[5] Ilnyckyj A (2010) Prevalence of idiopathic fecal incontinence in a community-based sample. Can J Gastroenterol 24(4):251-254.

[6] Borrie MJ, Davidson HA (1992) Incontinence in institutions: costs and contributing factors. Can Med Assoc J 147 (3): 322-328. 
[7] Tin RYT, Schulz J, Gunn B, Flood C, Rosychuk RJ (2010) The prevalence of anal incontinence in post-partum women following obstetrical anal sphincter injury. Int Urogynecol J 21 (8): 927932.

[8] Alnaif B, Drutz HP (2001) The prevalence of urinary and fecal Incontinence in Canadian secondary school teenage girls: questionnaire study and review of the literature. Int Urogynecol J 12 (1): 134-138.

[9] Botlero R, Davis SR, Urquhart DM, Shortreed S, Bell RJ (2009) Age-specific prevalence of, and factors associated with, different types of urinary incontinence in community-dwelling Australian women assessed with a validated questionnaire. Maturitas 62: 134-139.

[10] Franzén K, Johansson JE, Andersson G, Nilsson K (2008) Urinary incontinence: Evaluation of an information campaign directed towards the general public. Scand J Urol Nephrol 42: 534-538.

[11] Wooldridge LS (2009) Promoting continence awareness and community education. Ostomy Wound Manage 55: 4.

[12] Kang Y (2009) Knowledge and attitudes about urinary incontinence among community-dwelling Korean American women. J Wound Ostomy Continence Nurs 36: 194-199.

[13] Heit M, Blackwell L, Kelly S (2008) Measuring barriers to incontinence care seeking. Neurourol Urodynam 2008 27: 174-178.

[14] Berger MB, Patel DA, Miller JM, Delancey JO, Fenner DE (2011) Racial differences in selfreported healthcare seeking and treatment for urinary incontinence in community-dwelling women from the EPI study. Neurourol Urodynam 30(8):1442-1447.

[15] Buckley BS, Lapitan MC (2009) Prevalence of urinary and faecal incontinence and nocturnal enuresis and attitudes to treatment and help-seeking amongst a community-based representative sample of adults in the United Kingdom. Int J Clin Pract 63: 568-573.

[16] Sims J, Browning C, Lundgren-Lindquist B, Kendig H (2011) Urinary incontinence in a community sample of older adults: prevalence and impact on quality of life. Disabil Rehabil 33: 1389-1398.

[17] Swanson JG, Skelly J, Hutchinson B, Kaczorowski J (2002) Urinary incontinence in Canada: National survey of family physicians' knowledge, attitudes, and practices. Can Fam Physician 48: 86-92.

[18] This is Long-Term Care, 2015, Ontario Long Term Care Association.

[19] Seniors' Housing Report, 2014, Canadian Mortgage and Housing Corporation

[20] http://www.strategy-formulation.24xls.com/en510

[21] Taylor DW, Cahill JJ, Diaa EER (2013) Denial, Shame and Acceptance: Generating Base-line Knowledge and Understanding of Fecal Incontinence amongst Long-term Care Residents and Care Providers. Public Health Res 4(1) 13-18.

[22] The summative report of the raw survey data and questionnaires are available at www.cameroninstitute.org.

[23] http://hepeakperformancecenter.com/wp-content/uploads/2013/09/Learning-Pyramid.jpg 